\title{
Risk of intellectual disability in children born appropriate-for-gestational-age at term or post-term: impact of birth weight for gestational age and gestational age
}

\author{
Ruoqing Chen ${ }^{1} \mathbb{D} \cdot$ Kristina Tedroff $^{2} \cdot$ Eduardo Villamor $^{3} \cdot$ Donghao $^{\mathrm{Lu}^{4,5,6}} \cdot$ Sven Cnattingius ${ }^{1}$
}

Received: 31 May 2019 / Accepted: 22 November 2019 / Published online: 2 December 2019

(c) The Author(s) 2019

\begin{abstract}
Children born small for gestational age have a higher risk of intellectual disability. We investigated associations of birth weight for gestational age percentile and gestational age with risk of intellectual disability in appropriate-for-gestational-age (AGA) children. We included 828,948 non-malformed term or post-term AGA singleton children (including 429,379 full siblings) born between 1998 and 2009 based on data from the Swedish Medical Birth Register. Diagnosis of intellectual disability after 3 years of age was identified through the Patient Register. Using Cox regression models, we calculated hazard ratios (HRs) with 95\% confidence intervals (CIs) of intellectual disability among children with different birth weight percentiles and gestational age in the whole population and in a subpopulation of full siblings. A total of 1688 children were diagnosed with intellectual disability during follow-up. HRs (95\% CIs) of intellectual disability for the low birth weight percentile groups (10th-24th and 25th-39th percentiles, respectively) versus the reference group (40th-59th percentiles) were $1.43(1.22-1.67)$ and $1.28(1.10-1.50)$ in population analysis and $1.52(1.00-2.31)$ and 1.44 (1.00-2.09) in sibling comparison analysis. The increased risk for low birth weight percentiles in population analysis was stable irrespective of gestational age. A weak U-shaped association between gestational age and intellectual disability was observed in population analysis, although not in sibling comparison analysis. These findings suggest that among AGA children born at term or post-term, lower birth weight percentiles within the normal range are associated with increased risk of intellectual disability, regardless of gestational age.
\end{abstract}

Keywords Intellectual disability $\cdot$ Birth weight for gestational age $\cdot$ Gestational age $\cdot$ Cohort studies $\cdot$ Siblings

Electronic supplementary material The online version of this article (https://doi.org/10.1007/s10654-019-00590-7) contains supplementary material, which is available to authorized users.

\section{Ruoqing Chen}

ruoqing.chen@ki.se

1 Clinical Epidemiology Division, Department of Medicine Solna, Karolinska Institutet, 17176 Stockholm, Sweden

2 Department of Women's and Children's Health, Karolinska Institutet, Stockholm, Sweden

3 Department of Epidemiology, School of Public Health, University of Michigan, Ann Arbor, MI, USA

4 Department of Medical Epidemiology and Biostatistics, Karolinska Institutet, Stockholm, Sweden

5 Channing Division of Network Medicine, Brigham and Women's Hospital and Harvard Medical School, Boston, MA, USA

6 Department of Epidemiology, Harvard T.H. Chan School of Public Health, Boston, MA, USA

\section{Introduction}

Intellectual disability refers to a group of disorders characterized by significant cognitive limitations and limitation of adaptive functions that affects between 1 and $3 \%$ of the world's population $[1,2]$. Intellectual disability affects different aspects of life, including learning abilities, daily communication, self-care, social activities, etc. [1]. Fetal growth restriction may affect brain development and impair brain maturation and cognitive function [3]. Small for gestational age (SGA), defined as birth weight for gestational age below the population's 10th percentile, has been associated with lower IQ and intellectual disability [4, 5]. However, SGA is not identical to fetal growth restriction: some SGA infants are constitutionally small and have reached their growth potential, whereas larger infants, e.g., infants with appropriate birth weight for gestational age (AGA, i.e., birth weight for gestational age between 10th and 90th percentiles), may 
have not fulfilled their biological growth potential-the weight a fetus ought to achieve in the absence of pathological conditions [6-8]. Low birth weight percentiles within the range of AGA have been associated with higher risk of neonatal neurological morbidity, such as convulsion and hypoxic ischemic encephalopathy, but rarely been investigated for long-term neurological outcomes [5, 9]. The association between birth weight for gestational age percentile (hereinafter called birth weight percentile) and risk of intellectual disability in AGA children has, to the best of our knowledge, not been specifically investigated in a nationwide population-based setting.

Preterm birth $(<37$ gestational weeks $)$ is another known risk factor for cognitive deficits [10]. The risk of intellectual disability increases exponentially as gestational age decreases in preterm children [11, 12]. A similar trend of increasing risk by decreasing gestational age was recently shown in children born at term (37-41 weeks), whereas a trend of increasing risk by increasing gestational age was observed in children born post-term ( $\geq 42$ weeks) [12]. The same study also suggested a joint impact of term or postterm birth and SGA versus term birth and AGA. However, they did not explore the joint impact of birth weight percentile and gestational age within the AGA group.

Based on data from Swedish national registries, we aimed to investigate associations of birth weight percentile and gestational age with risk of intellectual disability in nonmalformed, term or post-term, AGA children. We performed population analysis and sibling comparison analysis, the latter of which was to control for unmeasured familial confounding factors shared by siblings. We also assessed the joint impact of birth weight percentile and gestational age with regard to risk of intellectual disability.

\section{Methods}

\section{Data sources}

This was a cohort study based on data from several Swedish national registries, including the Medical Birth Register, Patient Register, Cause of Death Register, Education Register, Total Population Register, and Multi-Generation Register. The unique personal identity number assigned to all Swedish residents enables individual record linkage between different registries [13]. The Medical Birth Register includes standardized antenatal, obstetric and neonatal information for almost all deliveries in Sweden [14]. Information is collected from the first visit to antenatal care and throughout pregnancy, delivery, and the neonatal period. The Patient Register includes nationwide information on hospital discharge diagnoses from 1987, and diagnostic information on hospital-based outpatient visits from 2001 onward [15].
The Cause of Death Register includes information on dates and causes of death [16]. The Education Register, updated yearly, includes information about highest level of formal education [17]. The Total Population Register provides information on individuals' demographic characteristics [18]. The Multi-Generation Register contains information on personal identity numbers of all first-degree relatives (i.e., parents, children, and siblings) of all residents in Sweden, which allows one to identify fathers and full siblings [19].

\section{Study participants}

We identified all singleton live born infants between January 1st, 1998 and December 31st, 2009 from the Medical Birth Register $(n=1,136,671)$. We excluded infants who had missing personal identity numbers $(n=13,980)$, infants whose mothers $(n=426)$ or fathers $(n=7724)$ had missing personal identity numbers, infants with missing data on gestational age $(\mathrm{n}=872)$, and infants with missing $(\mathrm{n}=3198)$ or implausible $(n=702)$ data on birth weight for gestational age, the latter of which were defined as values below or above the 5 times standard deviation from the mean. We restricted the study population to infants born AGA at term or post-term, and, as a result, we excluded 54,288 preterm infants, 85,721 SGA infants and 103,202 large for gestational age (LGA) infants (i.e., birth weight for gestational age above the 90th percentile). We also excluded infants who were diagnosed with major malformations (including congenital malformations, deformations, and chromosomal abnormalities) as recorded in the Medical Birth Register or in the Patient Register during the first year of age $(n=30,077)$ (Supplementary Table 1 for the Swedish version of International Classification of Diseases, tenth revision [ICD-10] codes for major malformations).

Since reliable and validated assessment tools of intellectual function such as the Wechsler scale measurements, utilized in Sweden and globally, are only partially available from 2 years and 6 months of age [20], children were followed from their third birthday until the date of first diagnosis of intellectual disability, date of death, date of emigration, or December 31st, 2012, whichever came first. As a result, children who died $(n=810)$ or emigrated $(n=6723)$ before 3 years of age were excluded, leaving 828,948 children in the final analysis. Among the 828,948 children, $429,379(51.8 \%)$ were full siblings.

\section{Exposure assessment}

Birth weight was recorded for infants immediately after birth. Gestational age was assessed by ultrasonography offered during the early second trimester for $87.4 \%$ of all births, by the last menstrual period for $7.5 \%$ of all births, and by a postnatal assessment for $5.2 \%$ of all births in the 
cohort. From the ultrasound-based, sex-specific Swedish reference curve for fetal growth [21], we calculated the $\mathrm{Z}$ scores of birth weight for gestational age, which were further converted to birth weight percentiles.

Birth weight percentiles were categorized into five groups: 10th-24th, 25th-39th, 40th-59th (reference), 60th-74th, and 75th-90th percentiles [9]. Gestational age was categorized into five groups: 37-38 weeks, 39 weeks, 40 weeks (reference), 41 weeks, and $\geq 42$ weeks. Birth weight percentiles and gestational age were also analyzed as continuous variables.

\section{Outcome ascertainment}

Intellectual disability was defined as a hospital contact (either hospitalization or outpatient visit) with a clinical diagnosis of ICD-10 codes F70-F79 from the Patient Register. The severity of intellectual disability was further classified using corresponding ICD-10 codes (Supplementary Table 1). In a sensitivity analysis, we redefined the outcome as at least two hospital contacts for intellectual disability on separate dates. Information about clinical diagnosis and dates of admission and discharge were extracted from the Patient Register.

\section{Covariates}

We identified maternal and neonatal variables that have been associated with both birth weight for gestational age/gestational age and risk of intellectual disability and might therefore confound the associations under study. As a result, we extracted information on maternal age at delivery [22, 23], parity [22, 24], smoking during pregnancy $[7,25]$, maternal height and weight collected at the first antenatal care visit, onset of labor [25, 26], mode of delivery [25, 27, 28], and child's sex [22, 29] from the Medical Birth Register. Body mass index (BMI) in early pregnancy $[22,30]$ was calculated by dividing measured weight $(\mathrm{kg})$ by self-reported height squared $\left(\mathrm{m}^{2}\right)$. We also included information on calendar period of delivery from the Medical Birth Register to control for temporal change in obstetric practice. We further obtained information about maternal educational level [31, 32] from the Education Register and country of birth [33, 34] from the Total Population Register. Maternal diabetic and hypertensive diseases $[7,25]$ were defined by a diagnosis of the corresponding ICD-10 codes registered in the Medical Birth Register (Supplementary Table 1 for ICD-10 codes). All covariates were analyzed as categorical variables (Table 1 for categorization of covariates).

\section{Statistical analysis}

We first calculated crude incidence rates of intellectual disability across categories of maternal and neonatal characteristics.

To assess the association between birth weight percentile and risk of intellectual disability, we calculated standardized incidence rates (SIRs) of intellectual disability across birth weight percentiles (every 10 percentiles), using the distribution of sex and year of delivery of the entire study population as the standard. As our study involved time-to-event data, we performed Cox proportional hazards regression and estimated hazard ratios (HRs) and 95\% confidence intervals (CIs) of intellectual disability across the five birth weight percentile groups with 40th-59th as the reference. Ordinary Cox regression was used for population analysis, and stratified Cox regression for sibling comparison analysis. In the sibling comparison analysis, only full siblings discordant for both exposure (i.e., siblings in different percentile groups) and outcome (i.e., siblings with different time-to-event) were informative and thus were included. Attained age was used as the underlying time scale in the Cox models. To assess the potential dose-response pattern across the entire spectrum of birth weight percentiles, we performed an additional analysis by including children born SGA and LGA. To assess the potential non-linear relationship of intellectual disability with birth weight percentile on a continuous scale, we additionally used restricted cubic splines with three knots positioned at the 10th, 50th and 90th percentiles of the distribution of the exposure variable. HRs were estimated using the 50th birth weight percentile as the reference. A similar analytic approach as described above was performed to assess the association between gestational age and risk of intellectual disability.

In population analysis, HRs were estimated after adjustment for maternal age, parity, educational level, country of birth, smoking, height, BMI, diabetic and hypertensive diseases, as well as child's sex, calendar period of delivery, onset of labor, and mode of delivery. In sibling comparison analysis, adjustment was made for maternal age, parity, smoking, BMI, diabetic and hypertensive diseases, and child's sex, calendar period of delivery, onset of labor, and mode of delivery. To account for the correlation among full siblings, we used a robust sandwich estimator to correct standard errors in all models.

We estimated the joint impact of birth weight percentile and gestational age with risk of intellectual disability, using children born at 40 weeks and with a birth weight for gestational age from 40th to 59th percentile as the reference category. Only population analysis was performed due to the small numbers of outcomes in the subpopulation of full siblings. 
Table 1 Maternal and neonatal characteristics and rate of any intellectual disability in term or post-term, non-malformed, appropriate-for-gestational-age children $(\mathrm{N}=828,948)$

\begin{tabular}{|c|c|c|c|}
\hline \multirow[t]{2}{*}{ Characteristics } & \multirow[t]{2}{*}{ No. of children (N[\%]) } & \multicolumn{2}{|c|}{ Intellectual disability } \\
\hline & & No. of cases & Rate $(95 \% \mathrm{CI})^{\mathrm{a}}$ \\
\hline Total & 828,948 & 1688 & $3.59(3.42-3.77)$ \\
\hline \multicolumn{4}{|l|}{ Mothers } \\
\hline \multicolumn{4}{|l|}{ Age at child's birth (years) } \\
\hline$<20$ & $13,964(1.7)$ & 35 & $4.28(3.08-5.97)$ \\
\hline $20-24$ & $107,263(12.9)$ & 267 & $4.28(3.79-4.82)$ \\
\hline $25-29$ & $261,025(31.5)$ & 514 & $3.32(3.05-3.62)$ \\
\hline $30-34$ & $291,290(35.1)$ & 522 & $3.21(2.94-3.50)$ \\
\hline$\geq 35$ & $155,406(18.8)$ & 350 & $4.27(3.85-4.74)$ \\
\hline \multicolumn{4}{|l|}{ Parity } \\
\hline 1 & $363,542(43.9)$ & 668 & $3.28(3.04-3.54)$ \\
\hline 2 & $309,995(37.4)$ & 618 & $3.51(3.25-3.80)$ \\
\hline 3 & $110,624(13.3)$ & 256 & $3.99(3.53-4.51)$ \\
\hline$\geq 4$ & $44,787(5.4)$ & 146 & $5.58(4.75-6.57)$ \\
\hline \multicolumn{4}{|l|}{ Educational level (years) } \\
\hline$\leq 9$ & $72,647(8.8)$ & 297 & $7.44(6.64-8.34)$ \\
\hline $10-11$ & $129,519(15.6)$ & 385 & $4.35(3.94-4.81)$ \\
\hline 12 & $217,397(26.2)$ & 398 & $3.36(3.04-3.70)$ \\
\hline $13-14$ & $118,133(14.3)$ & 208 & $2.92(2.55-3.35)$ \\
\hline$\geq 15$ & $286,624(34.6)$ & 375 & $2.50(2.26-2.76)$ \\
\hline Missing & $4628(0.6)$ & 25 & $13.60(9.19-20.13)$ \\
\hline \multicolumn{4}{|l|}{ Country of birth } \\
\hline Non-Nordic & $139,110(16.8)$ & 460 & $6.38(5.82-6.99)$ \\
\hline Nordic & $689,762(83.2)$ & 1227 & $3.08(2.92-3.26)$ \\
\hline Missing & $76(0.0)$ & 1 & $12.90(1.82-91.57)$ \\
\hline \multicolumn{4}{|l|}{ Smoking during pregnancy } \\
\hline No & $713,192(86.0)$ & 1384 & $3.48(3.31-3.67)$ \\
\hline Yes & $75,094(9.1)$ & 218 & $4.55(3.99-5.20)$ \\
\hline Missing & $40,662(4.9)$ & 86 & $3.45(2.79-4.26)$ \\
\hline \multicolumn{4}{|l|}{ Height $(\mathrm{cm})$} \\
\hline$<160$ & $105,464(12.7)$ & 291 & $4.90(4.37-5.50)$ \\
\hline $160-164$ & $211,505(25.5)$ & 488 & $4.05(3.71-4.43)$ \\
\hline $165-169$ & $242,573(29.3)$ & 438 & $3.17(2.89-3.48)$ \\
\hline$\geq 170$ & $257,073(31.0)$ & 437 & $3.02(2.75-3.32)$ \\
\hline Missing & $12,333(1.5)$ & 34 & $4.64(3.31-6.49)$ \\
\hline \multicolumn{4}{|l|}{ Early pregnancy BMI } \\
\hline$<18.5$ & $17,261(2.1)$ & 35 & $3.57(2.56-4.97)$ \\
\hline $18.5-24.9$ & $470,721(56.8)$ & 830 & $3.12(2.92-3.34)$ \\
\hline $25.0-29.9$ & $179,222(21.6)$ & 390 & $3.90(3.53-4.31)$ \\
\hline$\geq 30.0$ & $72,825(8.8)$ & 219 & $5.63(4.93-6.43)$ \\
\hline Missing & $88,919(10.7)$ & 214 & $3.84(3.36-4.39)$ \\
\hline \multicolumn{4}{|l|}{ Diabetic diseases } \\
\hline No & $820,494(99.0)$ & 1652 & $3.55(3.38-3.72)$ \\
\hline Pregestational diabetes & $2027(0.2)$ & 10 & $9.10(4.90-16.92)$ \\
\hline Gestational diabetes & $6427(0.8)$ & 26 & $7.66(5.22-11.25)$ \\
\hline \multicolumn{4}{|l|}{ Hypertensive diseases } \\
\hline No & $808,555(97.5)$ & 1632 & $3.56(3.39-3.74)$ \\
\hline Pregestational hypertension & $4197(0.5)$ & 10 & $4.80(2.58-8.92)$ \\
\hline Preeclampsia & $16,196(2.0)$ & 46 & $4.84(3.62-6.46)$ \\
\hline
\end{tabular}


Table 1 (continued)

\begin{tabular}{llcc}
\hline Characteristics & No. of children $(\mathrm{N}[\%])$ & \multicolumn{2}{l}{ Intellectual disability } \\
\cline { 4 - 4 } & & No. of cases & Rate $(95 \% \mathrm{CI})^{\mathrm{a}}$ \\
\hline Children & & & \\
Sex & & 1083 & $4.51(4.25-4.79)$ \\
Male & $423,549(51.1)$ & 605 & $2.63(2.43-2.85)$ \\
Female & $405,399(48.9)$ & & \\
Calendar period of delivery & & 845 & $3.44(3.22-3.69)$ \\
1998-2001 & $248,531(30.0)$ & 603 & $3.67(3.38-3.97)$ \\
2002-2005 & $277,384(33.5)$ & 240 & $3.98(3.51-4.52)$ \\
2006-2009 & $303,033(36.6)$ & & $3.36(3.19-3.55)$ \\
Onset of labor & & 3426 & $4.86(4.37-5.41)$ \\
Spontaneous & $688,715(83.1)$ & 20 & $3.68(2.38-5.71)$ \\
Induced & $133,292(16.1)$ & & \\
Missing & $6941(0.8)$ & 1267 & $3.38(3.20-3.57)$ \\
Mode of delivery & & 143 & $3.98(3.37-4.68)$ \\
$\quad$ Vaginal non-instrumental & $654,010(78.9)$ & 119 & $4.35(3.63-5.20)$ \\
Vaginal instrumental & $64,686(7.8)$ & 150 & $5.12(4.36-6.00)$ \\
Elective cesarean section & $52,469(6.3)$ & 9 & $3.81(1.98-7.33)$ \\
Emergency cesarean section & $54,583(6.6)$ & $3200(0.4)$ &
\end{tabular}

${ }^{a}$ Rate is calculated as number of cases per 10,000 person-years

To assess the robustness of the overall associations assessed above, we conducted two sensitivity analyses. First, since we used complete case analysis in the primary analysis, results might have been biased due to missing values of covariates (missing proportions were $0.01 \%, 0.6 \%, 0.8 \%, 1.5 \%, 4.9 \%$, and $10.7 \%$ for maternal country of birth, educational level, onset of labor, height, smoking during pregnancy, and BMI in early pregnancy, respectively). We repeated the Cox regression analysis with missing values imputed through multiple imputation using chained equations. Ten imputations with 50 iterations each were implemented. Second, to improve the validity of diagnosis of intellectual disability, we redefined the outcome as having had an intellectual disability diagnosis in at least two hospital contacts, and repeated both population and sibling comparison analyses.

To evaluate whether the associations of birth weight percentile and gestational age with risk of intellectual disability differed by severity of intellectual disability, we performed secondary analyses where we calculated SIRs and estimated HRs for each type of intellectual disability in both population and sibling comparison analyses.

Data preparation was performed using SAS version 9.4, SAS institute Inc, Cary, NC, USA. Statistical analyses were performed using Stata version 15.1, StataCorp LP, College Station, TX, USA.

\section{Results}

A total of 1688 children were diagnosed with intellectual disability during a median follow-up of 5.5 years (i.e., median age at the end of follow-up: 8.5 years). The median age at diagnosis was 6.1 years (interquartile range: $4.4-8.7$ years). The following maternal characteristics were related to higher incidence rates of intellectual disability among children: low $(<25$ years $)$ and high ( $\geq 35$ years) age at delivery, increasing parity, lower educational level, non-Nordic origin, smoking during pregnancy, shorter stature, overweight and obesity (BMI 25.0-29.9 and $\geq 30$, respectively), and diabetic or hypertensive diseases. Incidence rates were also increased for children delivered in more recent years, for children delivered by induced labor and by cesarean section, and for boys (Table 1). Similar patterns were also shown in the subpopulations of exposure- and outcome-discordant full siblings (Supplementary Tables 2 and 3).

\section{Primary analysis}

For birth weight for gestational age, the SIRs of intellectual disability peaked at the 10th birth weight percentile, 
Fig. 1 a Birth weight for gestational age percentiles and b gestational age and standardized incidence rates of any intellectual disability (population analysis). On the $\mathrm{X}$ axis of b, gestational age of 42 weeks represents 42 weeks and above
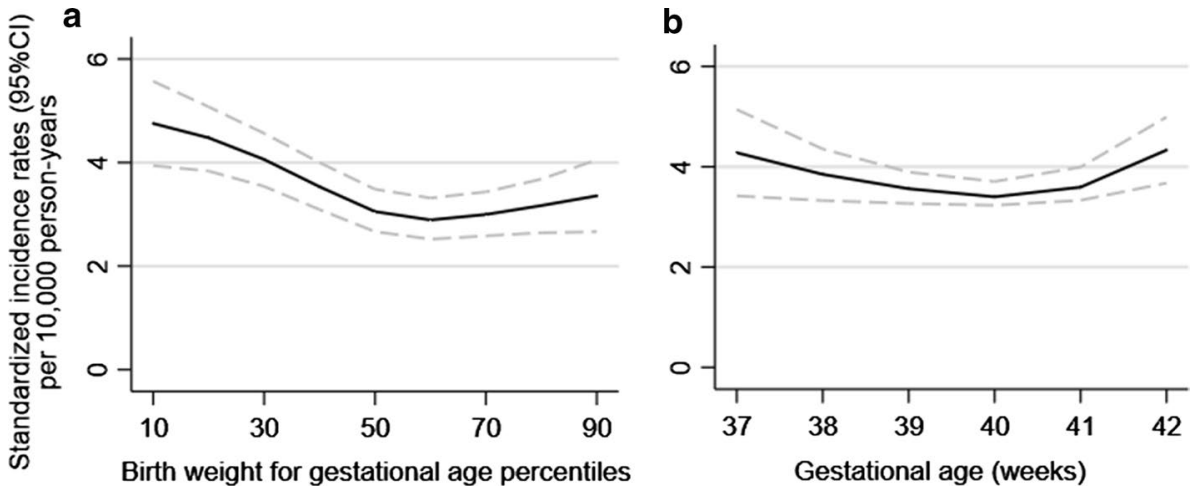

then decreased with increasing percentile, but leveled off from 50th percentile and beyond (Fig. 1a). For gestational age, the curve was less pronounced, and the lowest SIR was obtained at 40 weeks (Fig. 1b).

Compared with children born at the 40th-59th birth weight percentiles, children born at the 10th-24th percentiles were, in population analysis, at the highest risk of intellectual disability, but risks were also increased for children at the 25 th-39th percentiles (Table 2). Similar estimates were observed in sibling comparison analysis. No differences in risks were observed for children born at larger birth weight percentiles (60th-74th and 75th-90th) versus the reference group. When we also included children born SGA and LGA $(<10$ th and $>90$ percentiles, respectively), a clear dose-response pattern was seen across the entire spectrum of birth weight percentiles for both population analysis and sibling comparison analysis (Supplementary Table 4). In population analysis, children

Table 2 Birth weight for gestational age percentiles and gestational age and risk of intellectual disability in non-malformed, term or post-term, appropriate-for-gestational-age children (complete case analysis) $(\mathrm{N}=721,094)$

\begin{tabular}{|c|c|c|c|c|c|c|}
\hline \multirow[t]{3}{*}{ Characteristics } & \multicolumn{6}{|c|}{ Any intellectual disability } \\
\hline & \multicolumn{3}{|c|}{ Population analysis } & \multicolumn{3}{|c|}{ Sibling comparison analysis } \\
\hline & No. of children & No. of cases & HR $(95 \% \mathrm{CI})$ & No. of children & No. of cases & HR $(95 \% \mathrm{CI})$ \\
\hline \multicolumn{7}{|c|}{ Birth weight for gestational age percentiles } \\
\hline Total & 721,094 & 1415 & & 260,928 & 482 & \\
\hline 10th-24th & 136,786 & 338 & $1.43(1.22-1.67)$ & 43,641 & 113 & $1.52(1.00-2.31)^{\mathrm{a}}$ \\
\hline 25 th-39th & 141,509 & 307 & $1.28(1.10-1.50)$ & 53,677 & 120 & $1.44(1.00-2.09)^{\mathrm{b}}$ \\
\hline 40th-59th & 189,271 & 318 & Ref & 69,628 & 103 & Ref \\
\hline 60th-74th & 132,855 & 235 & $1.04(0.88-1.23)$ & 52,251 & 86 & $1.25(0.79-1.97)$ \\
\hline 75th-90th & 120,673 & 217 & $1.03(0.87-1.23)$ & 41,731 & 60 & $1.25(0.77-2.02)$ \\
\hline \multicolumn{7}{|c|}{ Gestational age (weeks) } \\
\hline Total & 721,094 & 1415 & & 245,625 & 456 & \\
\hline $37-38$ & 132,997 & 282 & $1.18(1.00-1.39)^{\mathrm{c}}$ & 40,987 & 80 & $1.33(0.82-2.16)$ \\
\hline 39 & 172,855 & 340 & $1.16(1.00-1.34)^{\mathrm{d}}$ & 60,831 & 113 & $0.96(0.65-1.41)$ \\
\hline 40 & 217,163 & 367 & Ref & 72,671 & 126 & Ref \\
\hline 41 & 140,970 & 284 & $1.17(1.00-1.36)^{\mathrm{c}}$ & 50,216 & 92 & $0.79(0.51-1.24)$ \\
\hline$\geq 42$ & 57,109 & 142 & $1.23(1.00-1.50)^{\mathrm{e}}$ & 20,920 & 45 & $1.07(0.57-2.01)$ \\
\hline
\end{tabular}

In population analysis, model was adjusted for maternal age at delivery, parity, educational level, country of birth, smoking during pregnancy, height, BMI in early pregnancy, maternal diabetic and hypertensive diseases, as well as child's sex, calendar period of delivery, onset of labor, and mode of delivery. In sibling comparison analysis, model was adjusted for maternal age at delivery, parity, smoking during pregnancy, BMI in early pregnancy, maternal diabetic and hypertensive diseases, and child's sex, calendar period of delivery, onset of labor, and mode of delivery ${ }^{\mathrm{a}} P=0.050$

${ }^{\mathrm{b}} P=0.053$

${ }^{\mathrm{c}} P=0.054$

${ }^{\mathrm{d}} P=0.041$

${ }^{\mathrm{e}} P=0.049$ 
born at 37-39 weeks were at higher risk of intellectual disability than children born at 40 weeks, and children born at 41 weeks or later were also at higher risk (Table 2). Such pattern was not observed in sibling comparison analysis. The smooth curves fitted for the relationships of birth weight percentile (continuous) and gestational age (continuous) with risk of intellectual disability displayed similar patterns (Supplementary Figures 1 and 2 respectively).

Table 3 shows the risks of intellectual disability by combinations of birth weight percentiles and gestational age. Compared with the reference group (40th-59th percentiles and 40 weeks' gestation), children born at 10th-24th and 25th-39th percentiles were at higher risk regardless of length of gestation. Birth weight percentiles between 60th and 74th rendered a pronounced risk increase for children born at 37-38 weeks. Children born at 75th-90th percentiles had a significant risk increase when they were born at 42 weeks or later.

\section{Sensitivity analysis}

Relative to the complete case analysis, similar overall associations of birth weight percentile and gestational age with risk of intellectual disability were observed after multiple imputation (Supplementary Table 5). Analyses where outcome was redefined as at least two diagnoses of intellectual disability also provided similar results regarding birth weight percentiles but showed weaker associations regarding gestational age (Supplementary Table 6).

\section{Secondary analysis}

Among all children with intellectual disability, $47 \%$ $(\mathrm{n}=787)$ had mild impairment. The SIRs of intellectual disability by severity across birth weight percentiles and gestational age are shown in Supplementary Figures 3 and 4 respectively. Similar to the overall association for any intellectual disability, the risk of mild intellectual disability was higher among children born at the 10th-24th and 25th-39th percentiles in population analysis and even higher in sibling comparison analysis. Risks of moderate and severe, other or unspecified types of intellectual disability were only significantly increased in children born at the 10th-24th percentiles in population analysis (Supplementary Table 7). Risks of mild and other or unspecified types of intellectual disability were higher in children born at 37-38 weeks, whereas risks of moderate and severe intellectual disability were higher in children born at 42 weeks or later in population analysis (Supplementary Table 8).

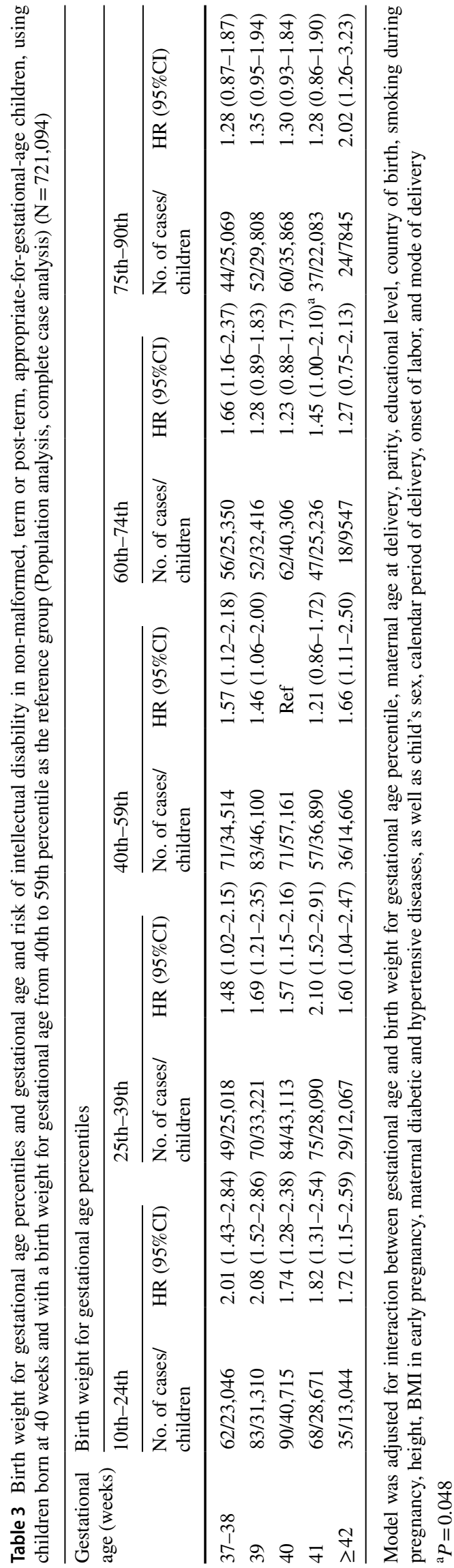




\section{Discussion}

In this nationwide population-based study of non-malformed, term or post-term, AGA children, we found that children born with lower birth weight percentiles had a higher risk of intellectual disability, both when compared with the general population, and with their siblings. A weak U-shaped association between gestational age and intellectual disability was observed in population analysis, indicating that children born early term or post-term had a higher risk of intellectual disability, although such pattern was not observed among siblings. The increased risk for low birth weight percentiles was stable irrespective of gestational age. Children with higher birth weight percentiles were at higher risk of intellectual disability if they were born post-term.

In agreement with previous studies [35], we found that children born SGA were at increased risk of intellectual disability. However, few studies, including no sibling design studies, have investigated the association between fetal growth and intellectual disability among AGA children. A previous Swedish study reported that birth weight for gestational age z-score was positively associated with intellectual performance among young men born at term, but did not examine differences between AGA and SGA or LGA [36]. A similar study on young Norwegian men showed that low birth weight for gestational age z-score was associated with higher risk of poor intellectual performance, but high z-score (except $>3.0$ ) was not associated with intellectual performance [37]. One study focusing on children noted that fetal growth, as assessed by percentage of optimal birth weight, was not associated with intellectual disability in AGA children [5]. This null finding may be due to differences in study population characteristics, statistical methods, and sample size. Our null results regarding higher birth weight percentiles seem to align with one previous study on intellectual capacity among LGA children compared with AGA children [38], but further studies are required to validate that higher birth weight percentiles in AGA children are not associated with risk of intellectual disability.

A number of studies have examined the association between gestational age and cognitive level in children born at term or post-term [12, 36, 39]. Our findings align with most of previous studies, which showed that early term or post-term birth was associated with a higher risk of intellectual disability, special education needs, and lower IQ scores [12, 36, 39-41]. The increased risk for children born post-term might indicate that a failure to be born full term (39-40 weeks) might relate to other congenital developmental conditions or that perinatal asphyxia related to post-term birth might have an adverse impact on brain development compared to full term birth [42]. A recent Swedish study, including the full range of birth weight percentiles, found an evident U-shaped association between gestational age and intellectual disability among siblings [12]. Our findings of non-significant associations in sibling design, which were based on a larger population (national data) and included only AGA children, might not be directly comparable but provide complementary evidence on variation in risk of intellectual disability among children born with appropriate weight and term gestation.

In this study, sibling comparison design was applied to control for unmeasured confounding factors shared by siblings. While associations regarding birth weight percentile persisted in sibling comparison analysis, associations for gestational age attenuated. This supports that variation in gestational age might be explained more by maternal genetic effect and shared (sibling) environment than other phenotypes such as birth weight [43]. Nevertheless, null findings may also imply an effect mediated only through familiar environment, which is completely "controlled away" in sibling comparison analysis [44].

The risk increase for lower birth weight percentile did not differ within the range of gestation age ( $\geq 37$ weeks). This suggests that even for full term infants, failure to reach their optimal growth potential may increase the tendency for intellectual and adaptive difficulties, potentially resulted from, e.g., reduced total brain volume $[45,46]$. On the contrary, higher birth weight percentiles were associated with higher risk of intellectual disability for post-term children, although not significant for 60th-74th percentiles, lending further support for interventions to deliver infants if pregnancy prolongation is considered hazardous [42].

Mild intellectual disability accounted for almost half of the cases and shows similar associations as any intellectual disability. The higher risk of mild intellectual disability for lower birth weight percentiles in sibling comparison analysis versus population analysis could, however, be a chance finding. The largely non-significant results for more severe and other types of intellectual disability may be attributed to lack of statistical power.

A strength of the present study is the use of prospectively and independently collected information on exposures, outcome, and covariates based on Swedish national registries, which yielded sufficient statistical power to evaluate the risk of intellectual disability. Ultrasonography was performed to the majority of women ( $87 \%$ of births) which ensured optimal pregnancy dating. In addition to population analysis, we applied sibling comparison analysis to adjust associations for unmeasured genetic and environment factors shared by siblings. Although restriction to siblings might induce selection bias, this might be less of a concern in the present study which showed similar distributions of characteristics between the entire study population and the subpopulations 
of exposure- and outcome-discordant siblings. Some potential limitations deserve mentioning. Complete case analysis may have induced bias due to missing covariate information, but the multiple imputation analysis, despite the assumption of missing data at random [47], provided similar and reassuring results. Residual confounding due to unmeasured confounders, such as maternal nutrition and parental intelligence, is possible [7, 48]. Multiple testing can lead to false positives but might be less of a problem in this study, as our main analysis only involved five statistical tests (Tables 2 and 3). We did not have sufficient statistical power to explore the joint impact of birth weight percentile and gestational age in the sibling design.

In conclusion, lower birth weight percentiles are associated with higher risks of intellectual disability in AGA children born term or post-term, irrespective of gestational age. This study enriches the knowledge of short- and longterm neurological outcomes of non-optimal fetal growth in AGA infants [9].

Acknowledgements Open access funding provided by Karolinska Institute. This study was approved by the Regional Ethical Review Board in Stockholm, Sweden (No. 2012/1813-31/4). In accordance with their decision, data linkage was allowed without informed consent from participants involved in the study. All individuals' information was anonymized and de-identified prior to analysis.

Funding This work was funded by the Swedish Research Council for Health, Working Life and Welfare (Grant No. 2017-00134), the National Institute of Mental Health (R21MH120824), and an unrestricted grant from Karolinska Institutet (No. 2368/10-221, Distinguished Professor Award to Dr Cnattingius).

\section{Compliance with ethical standards}

Conflict of interest The authors declare that they have no conflict of interest.

Open Access This article is distributed under the terms of the Creative Commons Attribution 4.0 International License (http://creativeco mmons.org/licenses/by/4.0/), which permits unrestricted use, distribution, and reproduction in any medium, provided you give appropriate credit to the original author(s) and the source, provide a link to the Creative Commons license, and indicate if changes were made.

\section{References}

1. Carey WB, Crocker AC, Coleman WL, Elias ER, Feldman HM. Developmental-behavioral pediatrics. 4th ed. Philadelphia: Elsevier; 2009.

2. Maulik PK, Mascarenhas MN, Mathers CD, Dua T, Saxena S. Prevalence of intellectual disability: a meta-analysis of population-based studies. Res Dev Disabil. 2011;32(2):419-36. https:// doi.org/10.1016/j.ridd.2010.12.018.

3. Morgane PJ, Austinlafrance R, Bronzino J, Tonkiss J, Diazcintra S, Cintra L, et al. Prenatal malnutrition and development of the brain. Neurosci Biobehav R. 1993;17(1):91-128. https://doi. org/10.1016/S0149-7634(05)80234-9.

4. Hollo O, Rautava P, Korhonen T, Helenius H, Kero P, Sillanpaa M. Academic achievement of small-for-gestational-age children at age 10 years. Arch Pediatr Adolesc Med. 2002;156(2):179-87.

5. Leonard H, Nassar N, Bourke J, Blair E, Mulroy S, de Klerk N, et al. Relation between intrauterine growth and subsequent intellectual disability in a ten-year population cohort of children in Western Australia. Am J Epidemiol. 2008;167(1):103-11. https ://doi.org/10.1093/aje/kwm245.

6. Malin GL, Morris RK, Riley R, Teune MJ, Khan KS. When is birthweight at term abnormally low? A systematic review and meta-analysis of the association and predictive ability of current birthweight standards for neonatal outcomes. BJOG. 2014;121(5):515-26. https://doi.org/10.1111/1471-0528.12517.

7. ACOG. ACOG Practice Bulletin No. 204: fetal growth restriction. Obstet Gynecol. 2019;133(2):e97-e109. https://doi.org/10.1097/ aog.0000000000003070.

8. Bukowski R. Fetal growth potential and pregnancy outcome. Semin Perinatol. 2004;28(1):51-8.

9. Cnattingius S, Kramer MS, Norman M, Ludvigsson JF, Fang F, $\mathrm{Lu} \mathrm{D}$. Investigating fetal growth restriction and perinatal risks in appropriate for gestational age infants: using cohort and withinsibling analyses. BJOG. 2018. https://doi.org/10.1111/14710528.15563 .

10. Volpe JJ. Cognitive deficits in premature infants. N Engl J Med. 1991;325(4):276-8. https://doi.org/10.1056/NEJM19910725325 0409.

11. Moster D, Lie RT, Markestad T. Long-term medical and social consequences of preterm birth. New Engl J Med. 2008;359(3):262-73. https://doi.org/10.1056/NEJMoa0706475.

12. Heuvelman H, Abel K, Wicks S, Gardner R, Johnstone E, Lee $\mathrm{B}$, et al. Gestational age at birth and risk of intellectual disability without a common genetic cause. Eur J Epidemiol. 2018;33(7):667-78. https://doi.org/10.1007/s10654-017-0340-1.

13. Ludvigsson JF, Otterblad-Olausson P, Pettersson BU, Ekbom A. The Swedish personal identity number: possibilities and pitfalls in healthcare and medical research. Eur J Epidemiol. 2009;24(11):659-67. https://doi.org/10.1007/s10654-009-9350-y.

14. Centre for Epidemiology. National Board of Health and Welfare. The swedish medical birth register-a summary of content and quality. 2003. https://www.socialstyrelsen.se/Lists/Artikelkatalog/ Attachments/10655/2003-112-3_20031123.pdf. Accessed 18 Mar 2019.

15. Ludvigsson JF, Andersson E, Ekbom A, Feychting M, Kim JL, Reuterwall C, et al. External review and validation of the Swedish national inpatient register. BMC Public Health. 2011;11:450. https://doi.org/10.1186/1471-2458-11-450.

16. Brooke HL, Talback M, Hornblad J, Johansson LA, Ludvigsson JF, Druid H, et al. The Swedish cause of death register. Eur J Epidemiol. 2017;32(9):765-73. https://doi.org/10.1007/s 1065 4-017-0316-1.

17. Statistics Sweden. The swedish register of education. 2004. http:// www.scb.se/statistik/UF/UF0506/Produktbeskrivning_short _English_UF0506_20040101r.doc. Accessed 18 Mar 2019.

18. Ludvigsson JF, Almqvist C, Bonamy AK, Ljung R, Michaelsson $\mathrm{K}$, Neovius M, et al. Registers of the Swedish total population and their use in medical research. Eur J Epidemiol. 2016;31(2):12536. https://doi.org/10.1007/s10654-016-0117-y.

19. Ekbom A. The Swedish multi-generation register. Methods in biobanking. Totowa: Humana Press; 2011.

20. Wechsler D. Wechsler preschool and primary scale of intelligence (Swedish Version). Stockholm: Sweden: Psykologiförlaget AB; 2005. 
21. Marsal K, Persson PH, Larsen T, Lilja H, Selbing A, Sultan B. Intrauterine growth curves based on ultrasonically estimated foetal weights. Acta Paediatr. 1996;85(7):843-8.

22. Huang J, Zhu T, Qu Y, Mu D. Prenatal, perinatal and neonatal risk factors for intellectual disability: a systemic review and meta-analysis. PLoS ONE. 2016;11(4):e0153655. https://doi.org/10.1371/ journal.pone. 0153655 .

23. Restrepo-Mendez MC, Lawlor DA, Horta BL, Matijasevich A, Santos IS, Menezes AM, et al. The association of maternal age with birthweight and gestational age: a cross-cohort comparison. Paediatr Perinat Epidemiol. 2015;29(1):31-40. https://doi. org/10.1111/ppe.12162.

24. Shah PS. Knowledge synthesis group on determinants of LBWPTb. Parity and low birth weight and preterm birth: a systematic review and meta-analyses. Acta Obstet Gynecol Scand. 2010;89(7):862-75. https://doi.org/10.3109/00016 349.2010.486827.

25. Langridge AT, Glasson EJ, Nassar N, Jacoby P, Pennell C, Hagan $\mathrm{R}$, et al. Maternal conditions and perinatal characteristics associated with autism spectrum disorder and intellectual disability. PLoS ONE. 2013;8(1):e50963. https://doi.org/10.1371/journ al.pone.0050963.

26. Shavit T, Ashual E, Regev R, Sadeh D, Fejgin MD, Biron-Shental $\mathrm{T}$. Is it necessary to induce labor in cases of intrauterine growth restriction at term? J Perinat Med. 2012;40(5):539-43. https://doi. org/10.1515/jpm-2011-0189.

27. Elter K, Ay E, Erenus M. Does the mode of delivery affect the birthweight? [corrected]. Eur J Obstet Gynecol Reprod Biol. 2003;109(2):138-40.

28. Delnord M, Blondel B, Drewniak N, Klungsoyr K, Bolumar F, Mohangoo A, et al. Varying gestational age patterns in cesarean delivery: an international comparison. BMC Pregnancy Childbirth. 2014;14:321. https://doi.org/10.1186/1471-2393-14-321.

29. Broere-Brown ZA, Baan E, Schalekamp-Timmermans S, Verburg BO, Jaddoe VW, Steegers EA. Sex-specific differences in fetal and infant growth patterns: a prospective population-based cohort study. Biol Sex Differ. 2016;7:65. https://doi.org/10.1186/s1329 3-016-0119-1.

30. Leddy MA, Power ML, Schulkin J. The impact of maternal obesity on maternal and fetal health. Rev Obstet Gynecol. 2008;1(4):170-8.

31. Raum E, Arabin B, Schlaud M, Walter U, Schwartz FW. The impact of maternal education on intrauterine growth: a comparison of former West and East Germany. Int J Epidemiol. 2001;30(1):81-7. https://doi.org/10.1093/ije/30.1.81.

32. Decoufle P, Boyle CA. The relationship between maternal education and mental retardation in 10-year-old children. Ann Epidemiol. 1995;5(5):347-53.

33. Kiserud T, Benachi A, Hecher K, Perez RG, Carvalho J, Piaggio G, et al. The World Health Organization fetal growth charts: concept, findings, interpretation, and application. Am J Obstet Gynecol. 2018;218(2S):S619-29. https://doi.org/10.1016/j. ajog.2017.12.010.

34. World Health Organization. World report on disability. 2011. https://www.who.int/disabilities/world_report/2011/report.pdf. Accessed 4 Sep 2019.

35. Arcangeli T, Thilaganathan B, Hooper R, Khan KS, Bhide A. Neurodevelopmental delay in small babies at term: a systematic review. Ultrasound Obstet Gynecol. 2012;40(3):267-75. https:// doi.org/10.1002/uog.11112.
36. Yang S, Bergvall N, Cnattingius S, Kramer MS. Gestational age differences in health and development among young Swedish men born at term. Int J Epidemiol. 2010;39(5):1240-9. https:// doi.org/10.1093/ije/dyq070.

37. Eide MG, Oyen N, Skjaerven R, Bjerkedal T. Associations of birth size, gestational age, and adult size with intellectual performance: evidence from a cohort of Norwegian men. Pediatr Res. 2007;62(5):636-42. https://doi.org/10.1203/PDR.0b013e3181 $5586 \mathrm{e} 9$.

38. Frank CE, Speechley KN, Macnab JJ, Campbell MK. Infants born large for gestational age and developmental attainment in early childhood. Int J Pediatr. 2018;2018:9181497. https://doi. org/10.1155/2018/9181497.

39. Yang S, Platt RW, Kramer MS. Variation in child cognitive ability by week of gestation among healthy term births. Am J Epidemiol. 2010;171(4):399-406. https://doi.org/10.1093/aje/kwp413.

40. Seikku L, Gissler M, Andersson S, Rahkonen P, Stefanovic V, Tikkanen M, et al. Asphyxia, neurologic morbidity, and perinatal mortality in early-term and postterm birth. Pediatrics. 2016;137(6):e20153334. https://doi.org/10.1542/peds.2015-3334.

41. MacKay DF, Smith GC, Dobbie R, Pell JP. Gestational age at delivery and special educational need: retrospective cohort study of 407,503 schoolchildren. PLoS Med. 2010;7(6):e1000289. https ://doi.org/10.1371/journal.pmed.1000289.

42. Glover Williams A, Odd D. Investigating the association between post-term birth and long term cognitive, developmental and educational impacts: a systematic review and Meta-analysis. J Matern Fetal Neonatal Med. 2008. https://doi.org/10.1080/14767 058.2018.1514379.

43. Lunde A, Melve KK, Gjessing HK, Skjaerven R, Irgens LM. Genetic and environmental influences on birth weight, birth length, head circumference, and gestational age by use of population-based parent-offspring data. Am J Epidemiol. 2007;165(7):734-41. https://doi.org/10.1093/aje/kwk107.

44. Sjolander A, Zetterqvist J. Confounders, mediators, or colliders: what types of shared covariates does a sibling comparison design control for? Epidemiology. 2017;28(4):540-7. https://doi. org/10.1097/EDE.0000000000000649.

45. Thompson DK, Kelly CE, Chen J, Beare R, Alexander B, Seal ML, et al. Early life predictors of brain development at termequivalent age in infants born across the gestational age spectrum. Neuroimage. 2019;185:813-24. https://doi.org/10.1016/j. neuroimage.2018.04.031.

46. de Bie HM, Oostrom KJ, Delemarre-van de Waal HA. Brain development, intelligence and cognitive outcome in children born small for gestational age. Horm Res Paediatr. 2010;73(1):6-14. https://doi.org/10.1159/000271911.

47. White IR, Royston P, Wood AM. Multiple imputation using chained equations: issues and guidance for practice. Stat Med. 2011;30(4):377-99. https://doi.org/10.1002/sim.4067.

48. Flensborg-Madsen T, Mortensen EL. Birth weight and intelligence in young adulthood and midlife. Pediatrics. 2017;139(6):e20163161. https://doi.org/10.1542/peds.2016-3161.

Publisher's Note Springer Nature remains neutral with regard to jurisdictional claims in published maps and institutional affiliations. 